\title{
Alexandra WALSHAM, Charitable Hatred. Tolerance and Intolerance in England, 1500-1700
}

Manchester, New York, Manchester University Press, coll. « Politics, Culture and Society in Early Modern Britain », 2006, XVI-364 p.

[paperback ed., 2009]

\section{Willem Frijhoff}

\section{(2) OpenEdition} Journals

\section{Édition électronique}

URL : http://journals.openedition.org/assr/21687

DOI : $10.4000 /$ assr. 21687

ISSN : 1777-5825

Éditeur

Éditions de l'EHESS

\section{Édition imprimée}

Date de publication : 31 décembre 2009

Pagination : 75-342

ISBN : 978-2-7132-2218-4

ISSN : 0335-5985

\section{Référence électronique}

Willem Frijhoff, « Alexandra waLSHAM, Charitable Hatred. Tolerance and Intolerance in England, 1500-1700 », Archives de sciences sociales des religions [En ligne], 148 | octobre-décembre 2009, document 148-131, mis en ligne le 27 janvier 2010, consulté le 21 septembre 2020. URL : http:// journals.openedition.org/assr/21687 ; DOI : https://doi.org/10.4000/assr.21687 


\section{Alexandra WALSHAM, Charitable Hatred. Tolerance and Intolerance in England, 1500-1700}

Manchester, New York, Manchester University Press, coll. « Politics, Culture and Society in Early Modern Britain », 2006, XVI-364 p.

[paperback ed., 2009]

\section{Willem Frijhoff}

\section{RÉFÉRENCE}

Alexandra WALSHAM, Charitable Hatred. Tolerance and Intolerance in England, 1500-1700, Manchester, New York, Manchester University Press, coll. « Politics, Culture and Society in Early Modern Britain », 2006, xvi-364 p. [paperback ed., 2009]

1 L'attention accrue portée aux rapports interconfessionnels comme constitutifs d'identités communautaires à l'époque moderne est certainement l'un des changements majeurs que l'histoire religieuse a connus depuis un quart de siècle. Son analyse passa tout d'abord par un renouveau du problème de la tolérance, puis par la reconnaissance du caractère contextualisé et construit des identités confessionnelles, y compris celle des catholiques eux-mêmes, enfin, en ce moment même, par l'exploration des rapports complexes entre identités confessionnelles et société globale. C'est bien évidemment dans les pays où la diversité religieuse joua un rôle social et culturel déterminant que les travaux ont été le plus fertiles, avec des accents propres à chaque communauté nationale: France (l'Édit de Nantes et sa Révocation), Allemagne (en particulier le rapport à la territorialité et la biconfessionalité), Pays-Bas (la liberté de conscience et la coexistence confessionnelle), l'Angleterre (l'apprentissage douloureux mais finalement efficace de la diversité), voire l'Europe centrale, dont le pluralisme religieux complexe demeure difficile à saisir pour un non-initié. En Grande-Bretagne, la recherche s'est renouvelée plus précocement qu'ailleurs, mais un peu à l'écart et 
parfois même à l'insu des grands débats continentaux, le paysage religieux et les rapports entre religion et politique y ayant à l'époque moderne des caractères tout à fait propres - que l'on pense à l'opposition entre des rois catholicisants et une Église anglicane nationale traversée elle-même de courants opposés, aux Puritains, aux Quakers, ou aux multiples sectes radicales aux noms fleuris comme les Muggletonians. En posant les bonnes questions et en dépolitisant le débat, des auteurs comme Patrick Collinson, Peter Lake, Diarmaid MacCulloch ou Michael Questier y ont patiemment décloisonnée une histoire religieuse peut-être encore plus victime du parti pris confessionnel que sur le continent européen. Alexandra Walsham, professeur d'histoire de la Réforme à Exeter et auteure d'une œuvre aussi savante que stimulante sur les rapports interconfessionnels en Grande-Bretagne, se situe à la croisée des différents débats. Charitable Hatred en profite pleinement pour proposer une nouvelle lecture, que je serais tenté de dire interculturelle, du problème de la tolérance en Angleterre à l'époque moderne. Un peu perdue dans une collection savante, son étude vient heureusement d'être republiée dans une édition brochée qui la rendra accessible à un public plus large.

2 Une première génération d'études sur la tolérance mit l'accent soit sur les rapports entre politique et religion, soit sur le discours intellectuel justifiant ou non la tolérance religieuse. Depuis lors, sans nier l'importance de ces deux facteurs, une histoire culturelle et religieuse renouvelée a insisté sur la primauté des rapports sociaux dans la construction des discours et des attitudes, et sur la nécessité de rendre compte des paramètres identitaires et de l'appropriation des valeurs en jeu. Du coup, la tentation de postuler dans le cours de l'histoire confessionnelle de simples rapports de forces politiques ou une évolution linéaire intellectuelle vers une tolérance accrue a dû céder devant le pragmatisme évident d'une négociation sociale et culturelle continue des rapports confessionnels, tantôt lente tantôt quasi quotidienne. Tout en se présentant intellectuellement comme l'évidente victoire de la vérité, leur issue demeurait en fait sujette aux aléas d'un complexe quasi inextricable de facteurs de tout ordre. Rendre justice à cette histoire, c'est la prendre telle qu'elle a dû se présenter aux contemporains, sans réductionnisme abusif. Aussi l'auteure se refuse-t-elle à définir $a$ priori les modalités, les limites, voire les termes mêmes de tolérance et d'intolérance qui, comme elle le montre clairement, pouvaient avoir des sens parfaitement opposés dans la bouche d'adversaires, voire dans un même groupe d'interlocuteurs placés dans des situations différentes ou ayant des rapports sociaux divergents. De même insiste-telle sur le fait que la persécution des minorités était non seulement une forme de violence sacrée au service de la vérité, répréhensible à nos yeux, mais aussi une arme de théologie pastorale, ayant valeur positive et didactique aux yeux des persécuteurs. Avant le travail intellectuel des Lumières radicales depuis Spinoza, mais même bien plus tard, la tolérance n'était donc point une valeur positive mais plutôt «la foi du perdant ». Elle entretenait un rapport complexe avec l'intolérance, comme le montrent les hésitations et réserves d'un John Locke et jusqu'à Pierre Bayle lui-même.

Contre l'idée simpliste d'une société foncièrement intolérante inexorablement remplacée par la société tolérante d'aujourd'hui, l'auteure construit sa démonstration du binôme multiforme tolérance/intolérance en six chapitres. Après une introduction historiographique - à mon sens un peu trop discrète à l'égard des travaux continentaux -, elle scrute d'abord les rapports et oppositions entre violence persécutrice et correction fraternelle des dissidents, en les liant à la genèse d'une Église nationale à la 
recherche de ses propres modalités de réalisation dans un contexte politique et confessionnel en perpétuelle ébullition. La disparité entre le dispositif légal et les pratiques localisées qui en résultent se retrouve dans le chapitre 3, où les différentes formes et modalités de conflit, d'opposition et de persécution sont examinées, en confrontant les croyances, imaginaires et pratiques populaires et les dispositifs formels de la communauté. L'image d'une société à haines religieuses féroces qui en résulte est soumise à la question dans les chapitres suivants. Comment en effet vivre en paix ou survivre au milieu d'une société apparemment hostile, comme ce fut de toute évidence le cas de la majorité des minorités tout au long de l'époque moderne? Existait-il un niveau de tolérance quotidienne qui pouvait dépasser par principe et en pratique les oppositions systématiquement présumées entre la bonne citoyenneté et la dissidence religieuse? Qui savait faire fi du désir de se singulariser civilement par des motifs religieux tels que l'élection divine ou la hantise du martyre ? Et par quels mécanismes cheminait-on cahin-caha vers l'acceptation d'un pluralisme légitimé dans les faits, à défaut d'une tolérance formalisée? Dans le dernier chapitre, la coexistence confessionnelle, acceptant le fait de la différence, est réexaminée dans la perspective plus large du continent européen, avec ses phénomènes de confessionnalisation et la genèse d'une pluralité de communautés confessionnelles à statut similaire, qui émerge partout au XVIII siècle. En face d'une tradition historiographique tendant à souligner l'originalité insulaire de la Grande-Bretagne, l'auteure y suggère timidement des similarités et convergences qui, je pense, demanderaient à être relevées et approfondies. Car cette société anglaise si haute en couleurs côté religieux était travaillée par des désirs, motifs et mécanismes parfaitement comparables à ceux du continent, et c'est à ce niveau-là que la recherche d'A. Walsham se situe et innove. 